\title{
Pengembangan Media Pembelajaran Berbasis Etnis Sumatera Utara
}

\author{
Uyuni Widiastuti $^{1}$, Adina Sastra Sembiring ${ }^{2}$, Mukhlis $^{3}$ \\ Program Studi Pendidikan Musik, Fakultas Bahasa dan Seni, \\ Universitas Negeri Medan \\ E-mail: uyunifbs@unimed.ac.id
}

\begin{abstract}
The development of instructional media in this paper is the development of learning media used in learning Arts and Culture class X High School in Pangururan District, Samosir Regency. The learning media developed are invincible with the syllabus in class X, namely "presentation of musical works". The objectives of this study were to: (1) develop traditional Karo music learning videos; (2) Developing Karo traditional music learning textbooks. This research uses a Research \& Development or research and development approach. The development of this learning media will be used by art teachers who are members of the MGMP (subject teacher deliberation) for Cultural Arts, especially art teachers in Pangururan District, Samosir Regency. The research conducted resulted in the development of instructional media in the form of learning videos for learning traditional Karo music and textbooks for learning traditional Karo music. The learning media developed in the form of learning videos for traditional Karo music includes the technique of playing Karo traditional music which is incorporated in the kulcapi drum ensemble whose instruments consist of kulcapi, keteng-keteng, and mangkuk. The next learning media is in the form of a textbook which contains the techniques for playing the kulcapi drum in the song Piso Surit and Terang Bulan. The two learning media that have been developed help the arts and culture teachers in carrying out the ethnicity of the ethnic North Sumatra.
\end{abstract}

Keywords: Development, Learning Media, Ethnicity, North Sumatra

\begin{abstract}
Abstrak: Pengembangan media pembelajaran pada tulisan ini merupakan pengembangan media pembelajaran yang digunakan pada pembelajaran Seni Budaya kelas X SMA di Kecamatan Pangururan Kabupaten Samosir. Media pembelajaran yang dikembangkan disesuaikan dengan silabus yang ada pada kelas X yaitu "penyajian Karya Musik". Tujuan penelitian ini adalah untuk : (1) Mengembangan video pembelajaran musik tradisional Karo; (2) Mengembangkan buku teks pembelajaran musik tradisional Karo. Penelitian ini menggunakan pendekatan penelitian Research \& Development atau penelitian dan pengembangan. Pengembangan media pembelajaran ini nantinya digunakan oleh guru-guru seni yang tergabung pada MGMP (Musyawarah Guru Mata Pelajaran) Seni Budaya, khususnya guru-guru seni yang ada di Kecamatan Pangururan Kabupaten Samosir. Penelitian yang dilakukan menghasilkan pengembangan media pembelajaran yang dalam bentuk video pembelajaran musik tradisional Karo dan buku teks pembelajaran musik tradisional Karo. Media pembelajaran yang dikembangkan dalam bentuk video pembelajaran musik tradisional Karo ini mencakup tentang teknik bermain musik tradisional Karo yang tergabung dalam ansambel gendang kulcapi yang instrumennya terdiri dari kulcapi, keteng-keteng dan mangkuk. Media pembelajaran selanjutnya dalam bentuk buku teks yang memuat tentang teknik dalam memainkan gendang kulcapi pada lagu Piso Surit dan Terang Bulan. Kedua media pembelajaran yang telah dikembangkan ini, membantu guru-guru Seni Budaya dalam mengajarkan musik berbasis etnis Sumatera Utara.
\end{abstract}

Kata Kunci: Pengembangan, Media Pembelajaran, Etnis, Sumatera Utara

\section{PENDAHULUAN}

Pendidikan seni dimulai dari jenjang pendidikan terendah (TK/PAUD), dasar (SD) menengah (SMP/SMA) hingga ke jenjang yang paling tinggi (Perguruan Tinggi). Secara umum materi pada pendidikan seni sama pada setiap jenjang, hanya tingkat kedalamannya saja yang berbeda yang disesuaikan dengan setiap karakteristik peserta didik. Ranah pada pendidikan seni terdiri dari dua, apresiasi (yang berkaitan dengan teori) dan ekspresi (yang berkaitan dengan praktek). Kedua ranah ini harus diimplementasikan pada siswa agar memberikan pengalaman berkesenian kepada siswa.

Pendidikan seni di jenjang menengah khususnya SMA ada pada mata pelajaran Seni Budaya yang didalamnya memuat empat bidang seni, yaitu seni musik, seni tari, seni rupa dan teater. Keempat bidang seni tersebut harus 
diajarkan oleh guru mata pelajaran Seni Budaya walaupun latar belakang pendidikan guru tersebut hanya pada satu bidang seni saja. Oleh sebab itu guru Seni Budaya harus memperluas wawasannya agar dapat memberikan materi seni lainnya kepada siswa. Hal ini juga dipertegas oleh penelitian Yanto, dkk (2019) bahwa faktor utama yang melatarbelakangi permasalahan pada pembelajaran yaitu materi, media, dan model pembelajaran yang masih konvensional dengan mengandalkan media analog dan media wacana, sehingga peserta didik mengalami kepasifan.

Hasil pengamatan yang telah dilakukan dengan guru-guru yang mengajar Seni Budaya kelas X SMA di Pangururan Toba Samosir, bahwa saat ini materi yang diajarkan pada siswa hanya diperoleh dari buku yang tersedia di sekolah, sehingga sumber tersebut sangat monoton dan sangat tidak bervariasi. Hal ini mengakibatkan pembelajaran yang kurang maksimal terlebih pada materi musik tradisional etnis Sumatera Utara, karena materi tersebut tidak tersedia di buku pegangan siswa maupun guru. Oleh sebab itu dengan dilakukannya pengembangan media pembelajaran yang berupa buku teks pembelajaran musik tradisional Karo dan video pembelajaran musik tradisional Karo sangat membantu guru-guru Seni Budaya dalam mengajarkan materi seni musik. Saat ini materi yang diberikan adalah pembelajaran musik tradisional Karo, yang dikhususkan pada teknik permainan alat musik Karo pada lagu Piso Surit dan Terang Bulan sebagai materi pembelajaran musik tradisional Karo. Tujuan penelitian ini adalah untuk: (1) mengetahui pengembangan video pembelajaran musik tradisional Karo; (2) mengetahui pengembangan buku teks pembelajaran musik tradisional Karo.

Pembelajaran adalah proses untuk membantu peserta didik agar dapat belajar dengan baik. Menurut Komalasari (2013) Pembelajaran merupakan suatu sistem atau proses membelajarkan pembelajar yang direncanakan, dilaksanakan dan dievaluasi secara sistematis agar pembelajar dapat mencapai tujuan-tujuan pembelajaran secara efektif dan efesien. Hal ini diperkuat oleh Sanjaya (2011) bahwa pembelajaran merupakan suatu sistem yang kompleks yang keberhasilannya dapat dilihat dari dua aspek yaitu aspek produk dan aspek proses. Keberhasilan pembelajaran dilihat dari sisi produk adalah keberhasilan siswa mengenai hasil yang diperoleh dengan mengabaikan proses pembelajaran. Keberhasilan pembelajaran dilihat dari sisi hasil memang mudah dilihat dan ditentukan kriteriannya, akan tetapi hal ini dapat mengurangi makna proses pembelajaran sebagai proses yang mengandung nilai-nilai pendidikan.

Media pembelajaran merupakan alat komunikasi antara sumber pesan (a source) dengan penerima pesan (a receiver), seperti televisi, film, diagram, bahan cetak, dan lainlain. Hal ini menunjukkan adanya hubungan antara medai dengan pesan dan metode. Menurut Gagne dalam Rusman (2012) media adalah berbagai jenis komponen dalam lingkungan siswa yang dapat memberikan rangsangan untuk belajar. Hal yang sama juga dikemukakan oleh Rayanda Asyar (2012) bahwa media pembelajaran dapat dipahami sebagai segala sesuatu yang dapat menyampaikan atau menyalurkan pesan dari sumber secara terencana, sehingga terjadi lingkungan belajar yang kondusif dimana penerimanya dapat melakukan proses belajar secara efisien dan efektif.

Media pembelajaran diklasifikasikan berdasarkan sifat, jangkauan dan teknik pemakaiannya:

a. Dari sifatnya, media dapat dibagi ke dalam:

1) Media auditif, yaitu media yang hanya dapat didengar saja atau media yang memiliki unsur suara.

2) Media visual, yaitu media yang hanya dilihat saja, tidak mengandung unsur suara

3) Media audiovisual, yaitu jenis media yang selain mengandung unsur suara juga mengandung unsur gambar yang bisa dilihat.

b. Dari kemampuan jangkauannya, media dapat pula dibagi ke dalam:

1) Media yang memiliki daya liput yang luas dan serentak

2) Media yang memiliki daya liput yang terbatas oleh ruang dan waktu

c. Dari cara atau teknik pemakaiannya, media dapat dibagi dalam:

1) Media yang diproyeksikan

2) Media yang tidak diproyeksikan.

\section{METODE}

Penelitian ini menggunakan pendekatan Pendekatan penelitian adalah Research \& Development atau penelitian dan 
pengembangan. Langkah-langkah pendekatan penelitian ini diantaranya: (1) Pendefinisian berisi masalah keterbatasan materi pembelajaran seni musik di kelas X; (2) pembuatan Video yang berisi rangkaian materi, dan shooting video; (3)Pembuatan buku teks, Teks; (4) hasil pengembangan divalidasi oleh ahlinya yaitu ahli materi seni musik dan ahli media pembelajaran.

Sumber data pada penelitian ini adalah: (1) Data Primer adalah data yang diperoleh secara langsung dari informan yaitu guru-guru Seni budaya kelas X SMA di Pangururan Toba Samosir; (2) Data Sekunder adalah data yang diperoleh dari sumber lain, seperti: buku, rekaman, silabus Seni Budaya kelas X atau dari sumber lainnya agar dapat menunjang data penelitian.

Menurut Miles \& Huberman dalam Sugiono (2014), analisis data terdiri dari tiga alur kegiatan, yaitu; (1) Reduksi Data, diartikan sebagai pemilihan, pemusatan perhatian, penyederhanaan, pengabstrakan dan transformasi data yang muncul di lapangan; (2) Penyajian data yang lebih baik merupakan suatu cara yang utama bagi analisis kualitatif yang meliputi matrik, grafik, jaringan dan bagan.; (3) Menarik Kesimpulan, selama penelitian berlangsung kesimpulan juga diverifikasi agar kesimpulan tidak hanya terjadi pada waktu pengumpulan data saja, namun perlu diverifikasi agar benar-benar dapat dipertanggungjawabkan.

\section{HASIL DAN PEMBAHASAN}

Media pembelajaran sangat dibutuhkan oleh semua guru dalam proses belajar mengajar, karena media pembelajaran merupakan alat bantu dalam menyajikan materi pembelajaran. Media Pembelajaran juga dapat dipergunakan untuk merangsang pikiran, perasaan, perhatian dan kemampuan atau ketrampilan siswa sehingga dapat mendorong terjadinya proses belajar sehingga memudahkan pencapaian tujuan pembelajaran yang sudah dirumuskan.

Guru yang kreatif hendaknya dapat merancang media pembelajaran yang disesuaikan dengan materi yang diberikan kepasa siswa. Kreativitas guru dalam mengembangkan media pembelajaran sangat menentukan keberhasilan dari sebuah pembelajaran, karena saat ini karakter siswa lebih kritis, oleh sebab itu maka guru yang kreatif dapat menyajikan pembelajaran dengan variasi metode dan media pembelajaran sehingga siswa dapat menerima materi dengan baik.

Mata pelajaran Seni Budaya dipelajari di setiap tingkatan pendidikan mulai dari SD (Seni Budaya dan Keterampilan), SMP dan SMA/SMK (Seni Budaya). Mata pelajaran Seni Budaya untuk tingkat SMP dan SMA/SMK memuat empat bidang seni, di antaranya seni musik, seni tari, seni rupa dan teater. Keempat bidang seni ini seharusnya diajar oleh masingmasing guru, namun kenyataan di sekolah hanya diajar oleh satu bidang seni saja sesuai latar belakang pendidikan si guru. Hal ini menyebabkan materi Seni Budaya tidak tersampaikan secara maksimal sehingga tujuan pembelajaranpun tidak tercapai. Oleh sebab itu perlu adanya pengembangan media pembelajaran untuk membantu guru-guru yang mengajar Seni Budaya di luar dari latar belakang pendidikannya.

Pengembangan media pembelajaran ini disesuaikan dengan materi yang ada pada buku yang digunakan pada mata pelajaran Seni Budaya, khususnya pada materi seni musik kelas X. Penelitian ini bekerjasama dengan MGMP SMA di Kecamatan Pangururan Kabupaten Samosir, oleh sebab itu maka media pembelajaran yang dikembangkan disesuaikan dengan silabus yang digunakan di kelas X SMA Pangururan Samosir.

Media pembelajaran yang digunakan pada pembelajaran musik haruslah disesuaikan dengan materi yang diajarkan, sehingga siswa lebih memahami materi yang dijelaskan oleh guru. Oleh sebab itu guru musik harus benarbenar tepat dalam memilih media pembelajaran, misalnya untuk materi tangga nada, maka guru musik harus menyediakan media pembelajaran seperti pianika, recorder, keyboard, gitar dan alat musik lainnya yang memiliki melodi. Terkadang sekolah maupun guru tidak memiliki media pembelajaran yang dapat digunakan dengan materi yang diajarkan, seorang guru yang kreatif harus mampu berkreasi untuk menggunakan media pembelajaran yang ada pada saat itu. Contoh lain dapat dilihat pada materi akord, apabila guru tidak memiliki alat musik harmonis (gitar, keyboard), maka dapat dilakukan dengan menggunakan suara (vokal) dengan menyuruh tiga orang siswa yang menyanyikan nada "do, mi, sol" yang dinyanyikan secara serentak.

Pengembangan media pembelajaran ini nantinya digunakan oleh guru-guru seni yang tergabung pada MGMP (Musyawarah Guru 
Mata Pelajaran) Seni Budaya, khususnya guruguru seni yang ada di Kecamatan Pangururan Kabupaten Samosir. Tidak menutup kemungkinan media pembelajaran yang dirancang pada penelitian ini nantinya akan digunakan oleh MGMP yang ada di daerah lainnya.

Sesuai silabus yang digunakan untuk kelas X semester I SMA di Kecamatan Pangururan Kabupaten Samosir, bahwa Standar Kompetensi yang harus dicapai adalah "Mengekspresikan diri melalui karya seni musik" dengan Kompetensi Dasar "Mengungkapkan musikal dan teknik bermain dalam musik tradisional daerah setempat". Biasanya guru musik mengajarkan musik tradisional sesuai dengan daerah tempat dia mengajar, namun karena musik tradisional Batak Toba sudah dikenal dan dipahami oleh siswa di Kecamatan Pangururan Kabupaten Samosir, maka materi ajar dikembangkan ke musik tradisional Karo. Hal ini dilakukan agar siswa mengenal musik-musik tradisional yang ada di Sumatera Utara.

\section{Pengembangan Video Pembelajaran Musik Tradisional Karo}

Media pembelajaran yang dikembangkan dalam penelitian ini adalah dengan membuat Video Pembelajaran yang dirancang semenarik mungkin, hal ini akan membuat siswa tertarik untuk belajar musik tradisional Karo. Media yang dikembangkan adalah VCD teknik permainan musik tradisional Karo dengan judul lagu "Piso Surit" dan "Terang Bulan". VCD yang dikemas untuk media pembelajaran berbeda dengan VCD yang ada dijual di pasaran. VCD yang dihasilkan akan menjadi turorial bagi siswa dalam memainkan musik tradisional karo, misalnya teknik memainkan kulcapi, teknik memainkan keteng-keteng, dan teknik memainkan mangkuk. VCD yang banyak dijual di pasaran adalah VCD yang sudah menjadi satu komposisi lagu "Piso Surit dan Terang Bulan", hal inilah yang membedakan antara VCD yang dirancang untuk media pembelajaran dengan VCD yang ada di pasaran. VCD yang dirancang disesuaikan dengan buku teks pembelajaran musik tradisional Karo, Berikut video pembelajaran musik tradisional Karo:

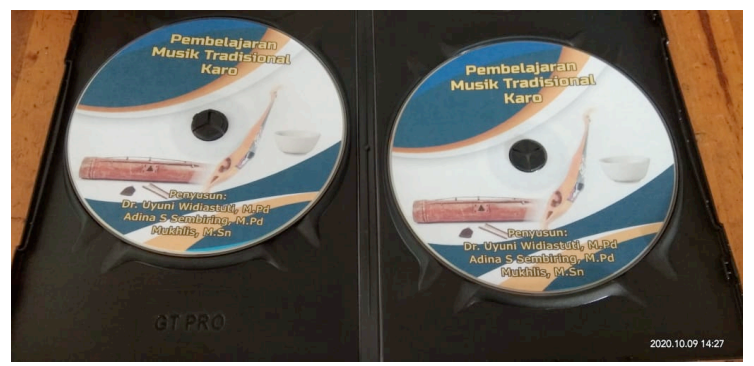

Gambar 1. VCD Pembelajaran Musik Tradisional Karo

\section{Pengembangan Buku Teks \\ Pembelajaran Musik Tradisional Karo}

Media pembelajaran lainnya yang dikembangkan adalah buku teks tentang musik tradisional Karo. Buku teks digunakan guru untuk buku penunjang dalam memberikan materi musik tradisional Karo. Hal ini sangat membantu sekali terlebih pada guru-guru yang belum pernah memainkan musik tradisional Karo, bahkan guru-guru yang berasal dari latar belakang pendidikan di luar seni musik. Secara umum buku teks memuat: jenis musik tradisional Karo, jenis lagu tradisional Karo, jenis alat musik tradisional Karo, teknik vokal pada lagu tradisional Karo, teknik bermain instrumen tradisional Karo, dan komposisi musik tradisional Karo. Secara khusus buku teks lebih fokus pada teknik memainkan instrumen musik Karo dalam memainkan lagu: Piso Surit dan Terang Bulan.

Penelitian ini mendeskripsikan rancangan buku teks yang disusun oleh peneliti untuk digunakan pada pembelajaran Seni Budaya pada materi musik Tradisional Karo. Buku teks yang dirancang oleh peneliti merupakan buku tentang teknik permainan gendang kulcapi (keteng-keteng, kulcapi, mangkuk) pada lagu Piso Surit dan Terang Bulan yang sesuai dengan VCD pembelajaran usik tradisional Karo. Buku teks yang dirancang sangat membantu guru-guru Seni Budaya Tingkat SMA dalam memberikan materi praktek musik tradisional karo. 


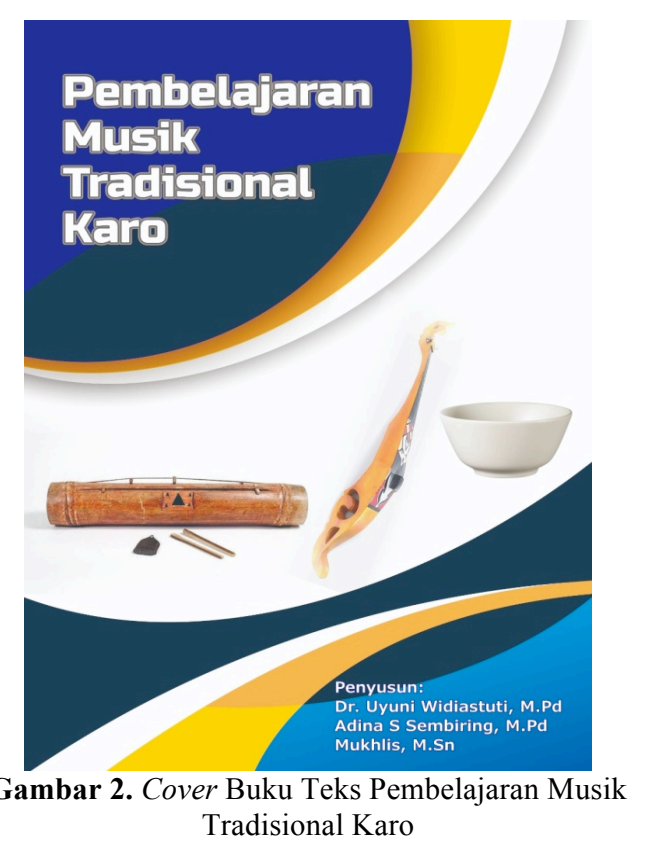

KESIMPULAN

Sesuai dengan judul "Pengembangan Media Pembelajaran (Buku Teks dan Video pembelajaran) Berbasis Etnis Sumatera Utara", maka media pembelajaran yang dikembangkan pada penelitian ini disesuaikan dengan kurikulum 2013 yang berlaku di SMA yakni materi yang ada pada kelas X. Materi tersebut disesuaikan dengan musik tradisional etnis Sumatera Utara khususnya pada lagu dan musik tradisional Karo. Media pembelajaran yang dikembangkan dalam bentuk video pembelajaran musik tradisional Karo ini mencakup tentang teknik bermain musik tradisional Karo yang tergabung dalam ansambel gendang kulcapi yang instrumennya terdiri dari kulcapi, keteng-keteng dan mangkuk. Media pembelajaran selanjutnya dalam bentuk buku teks yang memuat tentang teknik dalam memainkan gendang kulcapi pada lagu Piso Surit dan Terang Bulan. Kedua media pembelajaran ini (VCD da buku teks) dirancang saling berkaitan untuk mempermudah pembelajaran musik tradisional Karo. Dengan adanya kedua media pembelajaran yang telah dikembangkan ini, sangat membantu guru-guru Seni Budaya dalam mengajarkan musik berbasis etnis Sumatera Utara.

\section{DAFTAR PUSTAKA}

Anni,dkk, 2007, Psikologi Belajar, Semarang: UPT Unnes Press.

Basrowi, Suwandi, 2008, Memahami Penelitian Kualitatif, Jakarta: Rineka Cipta.

Dzamara, Zain.2010. Strategi Belajar Mengajar. Jakarta: Rineka Cipta, Edisi Revisi.
Fatimah, dkk, 2019, Development of Smart Content Model-Based Augmented Reality to Support Smart Learning, Journal of Science Learning, v2 n2 p65-70 2019.

Hadi, Rizali, dkk, 2017, Economic Learning Media Development Based on Local Locality, International Journal of Higher Education, v6 n3 p188-194.

Jung, Kiho; Otaka, Yuki, 2019, The Introduction of a Thin-Bending Wood Horn Speaker as Multipurpose Teaching Material in Japanese Junior High School Technology Classes. World Journal of Education, v9 n6 p57-64.

Liliarti, dkk, 2018, Improving the Competence of Diagrammatic and Argumentative Representation in Physics through Android-Based Mobile Learning Application. International Journal of Instruction, v11 n3 p107-122 Jul.

Miles \&Huberman, 1996, Analisis Data Kualitatif, Jakarta: Universitas Indonesia Press.

Rayandra, Asyar. 2012. Kreatif Mengembangkan Media Pembelajran. Jakarta: Gaung Persada Press.

Rusman, dkk, 2012. Pembelajaran berbasis Teknologi Informasi dan Komunikasi, Jakarta: PT Grafindo Persada.

Sibarani, Robet, 2012, Kearifan Lokal : Hakikat, Peran dan Metode Tradisi Lisan, Jakarta : Asosiasi tradisi lisan (ATL).

Sugiono, 2014. Metode Penelitian Pendidikan Kuantitaif dan Kualitatif, $R \& D$, Bandung: Alfabeta.

Tarigan, Henry Guntur dan Djago Tarigan. 2009. Telaah Buku Teks Bahasa Indonesia. Bandung: Penerbit Angkasa.

Warigan, 2012, Pengembangan karakter berbasis kearifan lokal hamemayu hayuning bawana (identifiksdi nilai-nilai karakter berbasis budaya, Yogyakarta: Universitas Negeri Yogyakarta.

Wahyuni, S, 2013. Keberagaman Dan Makna Nilai Kerifan Lokal Sebagai Sumber Inspirasi Pembelajaran Seni Budaya Yang Berkarakter. Madiun.

Yunanto Tri Laksono, Ardian Jaya Prasetyo, Dhika Yuan Yurisma. 2019. Media Pembelajaran Interaktif Berbasis Software Fruity Loops Untuk Meningkatkan Pembelajaran Mata Kuliah Tata Suara. VIRTUOSO (Jurnal Pengkajian Dan Penciptaan Musik), Vol. 1 No. 2, Juni 2019. ISSN: 2622-0407 